\title{
Does Technical Progress Stimulate the Low-Carbon Transformation Process in China? A Provincial Aspect
}

\author{
Qiaozhi Zhao ${ }^{1 *}$, Yanhong Li ${ }^{1}$, Qingyou Yan ${ }^{1}$, Lijun Zhang ${ }^{2}$ \\ ${ }^{1}$ School of Economics and Management, North China Electric Power University, Baoding China \\ ${ }^{2}$ State Grid Zhejiang Economy Research Institute, Hangzhou, China
}

Received: 2 August 2018

Accepted: 25 November 2018

\begin{abstract}
How to stimulate technical progress development among provinces is of great significance in order for China to achieve high-quality economic development. Spatial statistical methods are applied to analyze their spatial characteristics of technical progress and its influential effect on carbon dioxide emissions. Results are as follows: (1) Moran index and Moran scatter diagram are used to analyze spatial distribution features among provinces in terms of technical progress. It presents a significant, positive spatial cluster state and is dominated by the 'Lower-Lower' (L-L) type. Spatial spillover effects should not be ignored. (2) Spatial Durbin model (SDM) is applied to analyze technical influential effects on carbon dioxide emissions. Technical progress impacts itself in a negative way. Cleaner technical progress among provinces is dominated during the whole research period. Its indirect effects on neighbors are positive and insignificant. Total effect is close to zero. 'L-L'-dominated spatial distribution of technical outputs is not beneficial for stimulating reduction effects by technical spillovers among provinces. (3) When regional technical development incentive policies are arranged to accelerate low-carbon transformation, green technical progress should be placed in the priority order. Their spatial optimization also puts more focus upon it. The Yangtze River Delta, Pearl River Delta and Beijing-Tianjin-Hebei regions should be the first R\&D centers to accelerate spatial transmissions.
\end{abstract}

Keywords: technical progress; carbon dioxide emissions; spatial distribution, spatial Durbin model

\section{Introduction}

Low carbon transformation has become an important subject to realize high quality development for China nowadays. Its carbon dioxide emissions occupied 27.3 percent of the world in 2016, which exceeded

*e-mail: zhaoqiaozhi2006@126.com the sum of emissions from US and EU and were 7.65 times the emissions in Japan [1]. International calls for more responsibilities for carbon emissions exert more and more pressure on the low-carbon transformation process. How to accelerate this process and realize absolute emissions reduction are the best choice for central government to answer for international calls and improve economic development quality. On one hand, technical progress is the core driving force to realize low-carbon transformation [2]. Low-carbon 
energy supply, industrial sectors' production and their structure arrangement rely on technical progress finally. Thus, how to stimulate technical development is a great significant subject to accelerate the lowcarbon transformation process. Such measures as R\&D funds input, technical outputs and spatial structures, etc., should be considered in detail. Especially, green technical progress development should be given the priority. On the other hand, inadequate and imbalanced development problems are apparent in terms of technical progress among regions. These have become an obstacle to accelerate the transformation process. Spatial distribution optimization can save R\&D resource input, and spillovers among regions can give full paly to emissions reduction effects. Since 2000, technical progress in China has been developing at high speed. For instance, annual growth rate of authorized patent output in China was greater than 20 percent during 2001-2016. Meanwhile, regional disparities among regions in terms of technical development also cannot be neglected. Provincial disparity in terms of authorized patent per capita among provinces kept more than 20 times during the period. In 2003, it peaked 56.6 times. Spatial disparity features should be considered in detail during technical development arrangements for the central government. According to the first geography economics laws (Tobler, 1979), there exist close relationships among adjacent regions [3]. Spatial autocorrelation is also included in policy arrangement. Based on the above analysis, spatial clusters and heterogeneity characters should be evaluated before considering its effects upon carbon dioxide emissions. Therefore, this research is carried out from spatial distribution characters among provinces in China during the research period and then its influences upon carbon dioxide emissions will be considered in detail. Suggestions shall be made for central governments' references in terms of identifying the prior development provinces and improving spatial spillover effects among 30 provinces in order to accelerate the whole transformation process in China.

In the literature, technical influences on pollutant emissions has become a key subject for researchers today. Most literature focuses on technical progress evaluation and its transmission mechanism analysis. In technical progress evaluation research, data envelopment analysis (DEA) and Malmquist index methods are applied in order to obtain technical progress information. In this framework, economic output is regarded as expected output, and carbon dioxide emissions are included as the unexpected output. Han C. (2018) applied 'DEA+Malmquist index decomposition' framework to the low-carbon technical progress index values and explore its reduction effects of industrial sectors [4]. Zhang B. (2017) [5], Xie B. and Song Y. (2017) [6], Cheng et al. (2017) [7], Sun X. et al. (2016) [8], Jin P. (2017) [9], Ji K. and Qu R. (2012) [10] et al. used this framework to evaluate technical trends and further analyzed their influential effects in China. Besides, some researchers use such statistical indexes as
R\&D funds input, human resources input or technical output indexes to reflect technical trends. Zhang C. and Zhang Z. (2015) utilized FDI, R\&D fund input, human capital input and authorized patent indexes to evaluate technical progress trends in China [11]. Wei W. and Yang F. (2010), Huang J. and Ding G. (2014), Yin J. et al. (2015), Zhou H et al. (2016), Zhou Z. et al. (2017), Zhao Q.Z. and Yan Q.Y. (2018) employed patent output index to evaluate technical trends [12-17]. When DEA framework is utilized, evaluation results are concluded based on the relative efficiency compared with production frontiers, and they are much dependent on sample selection. Therefore, results are sensitive to abnormal values and have poor stability. To avoid the result stability problem, more researchers have chosen statistical indicators to reveal technical trends. Compared with technical input indicators, technical output indicators can supply more exact information. Thus, an authorized patent output indicator is selected in this research in order to evaluate technical development trends among provinces in China.

In terms of technical influence on carbon emissions research, the two main directions are mechanism and empirical analysis. With respect to influential mechanisms, Jaffe (2002) pointed out that technical progress may lead to pollutant emissions rising or decreasing [18]. Shen M. et al. (2012) divided its influence effects into two ways: direct and indirect effects [19]. The direct effect was the path of 'technical progress $\rightarrow$ carbon dioxide emissions' and it meant that technical progress directly inflects emissions. An undirected effect was referred to the way 'technical progress $\rightarrow$ economic growth $\rightarrow$ carbon dioxide emissions' and technical progress stimulated emissions change by economic growth. Technical progress had path dependence and depended on its initial technical structure. Acemoglu et al. (2009) classified technical progress into two types: pollutant and clean technology [20]. When pollutant technical progress dominated, technical progress pushed pollutant sectors to expand at a higher speed and promote carbon dioxide emissions ascending. Otherwise, when cleaner technical progress dominated technical progress, it stimulates clean sectors to produce more goods and edge out pollutant goods. At the end, less fossil energy is consumed and fewer emissions are produced. Yan Z.M. and Deng X.L. (2016) analyzed direct effect and possible indirect effects on industrial carbon dioxide emissions, from theoretical mechanism and empirical model aspects [21]. In summary, there is much uncertainty surrounding technical influences on carbon dioxide emissions and it depends on transmission path and technology structure of the economics.

Decomposition methods and econometric models are used in the influential factor analysis in current literature. IDA (index decomposition analysis) and SDA (structural decomposition analysis) are the two widely used decomposition methods. LMDI (logarithmic mean divisia index) is the most popular IDA method, 
which is widely used in recent energy or emissions analysis. Sun N. (2010) used LMDI to analyze the main factors that influence manufacturing sectors' carbon emissions in China and pointed out the driving effects from technical progress [22]. Liao and $\mathrm{Xu}$ (2017) and Dong F. et al. (2018) decomposed the driving effects in carbon dioxide emissions with SDA framework [23-24]. Under decomposition method framework, the accidental factor is not taken into consideration and conclusions may deviate from reality. In the econometric model, accidental factor is included in the model as random variable $\varepsilon$. Influential effects can be evaluated by parameter estimation results and statistical tests. As panel data supply individual and dynamic information simultaneously, panel data econometric models are widely utilized by many researchers during factor analysis. Common panel data econometric model and spatial panel data econometric model are often constructed to explore technical progress effect on carbon emissions. [25-29] applied the panel data econometric model to analyze technical progress factor's influence on carbon dioxide emissions. They mainly differ in explained variable selection and parameter estimation results.

In a summary, current research mainly focuses on technical progress trends under DEA framework and results have poor stability. A statistical indicator can provide precise data information and its results can be more stable and referable for implementing low carbon incentives. The main contributions of this research are as follows. Firstly, authorized patent indicator is chosen as the evaluation indicator to reveal technical progress information among provinces. Moran's index (Moran I) and Moran scatter diagram (MSD) are used to reveal its spatial characteristics. Secondly, the spatial econometric model is constructed to analyze its influence on carbon dioxide emissions and technical progress is the core variable. Results can explain not only its direct effects, but also the indirect effects to its neighbors' emissions. Conclusions will provide detailed references for the central government to stimulate technical development incentive policies and coordinate regional low-carbon transformation plans in China.

\section{Material and Methods}

\section{Spatial Character Analysis}

Moran I and MSD are the usually used statistical methods to analyze the spatial distribution character of a sample. Moran I is obtained according to Eq. (1), and it varies within the range $[-1,1]$. When it is positive, it indicates a wholly positive spatial cluster character. When it is negative, it shows a negative spatial cluster character. When it ranges at zero, it reveals that there are no spatial autocorrelations and no clusters in a whole among individuals. Its significance test is to examine whether it is a significant effect for this variable. When it is rejected, it means spatial cluster character is important and it should not be neglected from consideration. In Eq. (1), $W$ is defined as spatial adjacency matric and $W_{i j}$ reveals the spatial adjacency features among the two individuals. When they are spatial neighbors, it is 1 and otherwise it is given zero. $\bar{X}$ and $S^{2}$ are the mean and variance of indicator $X$ :

$$
\text { Moran } I=\frac{\sum_{i, j} W_{i j}\left(X_{i}-\bar{X}\right)\left(X_{j}-\bar{X}\right)}{S^{2} \sum_{i, j} W_{i j}}
$$

MSD is utilized to analyze local spatial heterogeneity characters by its four quadrants. Four quadrants reveal four types and they are ' $\mathrm{H}-\mathrm{H}$ ', 'L-H', 'L-L' and ' $\mathrm{H}-\mathrm{L}$ ' types, respectively. ' $\mathrm{H}-\mathrm{H}$ ' and 'L-L' reveal positive spatial clusters locally. 'H-H' shows both higher properties for two neighbors. And if they are of ' $\mathrm{L}-\mathrm{L}$ ' type, they represent both lower properties. 'L-H' and 'H-L' types reveal a locally negative cluster state. Of ' $\mathrm{L}-\mathrm{H}$ ' type, individuals with lower values are spatially adjacent to those with higher values. On the above analysis in terms of technical progress, spatial heterogeneity character among provinces can be concluded.

\section{Spatial Panel Data Econometric Model}

The econometric model is used to explain influences with its parameter estimation results and statistical test conclusions. Panel data can provide individual and timing information simultaneously of the sample. The econometric model with panel data is defined as panel data econometric model (PDEM) and widely applied to factor analysis in current research. It is classified into two types: common panel data econometric model (CPDEM) and spatial panel data econometric model (SPDEM). In CPDEM, individuals are assumed to be independent and inter-individual interaction is neglected. In SPDEM, spatial adjacency matric (W) is included into the model to reveal interactions among individuals. SPDEM is further divided into three sub-types: spatial lag model (SLM), spatial error model (SEM) and spatial durbin model (SDM). In SLM, spatial lag variable $W y$ is introduced into the model. In SEM, $W \varepsilon$ is included into the model as an explanatory variable. $W y$ and $W \varepsilon$ are both introduced into the model in SDM. SDM is usually constructed when spatial spillover effect is considered. Statistical test results are helpful for confirming whether it is converted into SLM or SEM.

A series of statistical tests should be carried out to obtain reliable parameter estimation results and obtain analysis conclusions. They are mainly panel unit root tests, panel co-integration tests, models form selection tests, significance tests and robust tests, etc.

Firstly, panel unit root tests and co-integration tests are implemented before the econometric model 
is constructed. They are intent on examining stable, long-term equilibrium relationship existence among variables. Panel unit root tests are to explore the stability features for variables and mainly conclude LLC, Fisher ADF and Fisher PP tests. The null hypothesis is that there is a general unit root in LLC test and it is an effective unit root in the other two tests. Only when variables have the same order stable property can panel co-integration tests be implemented to examine whether there is a long-term equilibrium relationship among variables. Otherwise, false regression results may be obtained. Kao test is used in the co-integration test. Its null hypothesis assumes that there is no long-term co-integration relationship among variables. If the null hypothesis is refused, stable long-term equilibrium relationships among variables exist and the econometric model should be constructed.

The second type of statistical test is about fixed effect model forms of selection tests. There are four fixed effect model forms and they are models with fixed effects: mixed fixed, individual fixed, time fixed and dual fixed effect. Statistical tests mainly conclude R square $\left(R^{2}\right)$, log-likelihood test (Log-L), and Lagrange multiplier (LM-lag, LM-error, robust LM-lag and robust LM-error). The third type of statistical test is to examine how SDM should be converted into SLM or SEM. The conclusion is based onstatistics, Wald test (Wald_spatial_lag, Wald_spatial_error) and likelihood ratio test ( $L R, L R \_s p a t i a l \_l a g$ and $\left.L R \_s p a t i a l \_e r r o r\right)$ results.

Finally, robust tests of parameter estimation results in the model should be implemented to confirm that results are robust by variables or data change. In this section, two substitute variables for the core explanatory variable are chosen to explore out the robustness results. Besides, the middle part of the research period (2005-2012) is chosen to estimate parameters and examine the robust results of the model.

All variables are converted into the logarithm forms in order to eliminate the heteroscedasticity phenomena among variables in the model and they are represented by $\ln (\cdot)$

\section{Results and Discussion}

\section{Spatial Distribution Characters of Technical Progress}

In this section, an authorized patent indicator is chosen to reveal their spatial characters and dynamic trends during 2001-2016. Moran indexes and MSDs are obtained during the period and they are shown in Table 1 and Fig. 1.

From Table 1, Moran Index turned from an insignificant indicator to significant one and the critical year was 2007. Before 2007, it was not wholly significant and it revealed that spatial effect was not an important factor in terms of technical development. During 2007-2016, spatial effect among provinces was an important influential factor and should be considered when technical policies were implemented. Moreover, Moran index was kept positive during the whole period. Positive spillovers dominated among the provinces in terms of tehcincal progress. It kept an apparently rising trend and increased by 28.89 percent totally during 2007-2016. In 2016, it was 0.2311 and still located at a lower level. In summary, technical progress represents a positive, lower-level spatial cluster character among 30 provinces.

Fig. 1(a-b) are the MSDs in 2011 and 2016, respectively. With comparison, spatial heterogeneity trends are analyzed. In Fig. 1b), 6 provinces are located in the first quadrant and 17 provinces in the third quadrant. They occupied $20 \%$ and $56.67 \%$ of 30 provinces, respectively. ' $\mathrm{L}-\mathrm{L}$ ' is the dominant spatial cluster type and reveals that many provinces with lower technical output form spatial clusters in China. It is not suitable for technical spillovers among them. 'L-H' and ' $\mathrm{H}-\mathrm{L}$ ' types occupied $13.33 \%$ and $10 \%$, respectively. Compared with MSD in 2011, a few provinces took spatial transition during 2011-2016. For instance, Fujian Province is located in the secondary quadrant in 2011 and changed to the first quadrant in 2016. Sichuan Province transferred from the third to fourth quadrant, which indicates that

Table 1. Moran I values of technical progress during 2001-2016 ( $\alpha=5 \%$ ).

\begin{tabular}{|c|c|c|c|c|c|c|c|}
\hline Year & Moran I & p-value & Sig. test & Year & Moran I & p-value & Sig. test \\
\hline 2001 & 0.0664 & 0.1470 & No & 2009 & 0.2442 & 0.0240 & Yes \\
\hline 2002 & 0.0829 & 0.0990 & No & 2010 & 0.2530 & 0.0230 & Yes \\
\hline 2003 & 0.1612 & 0.1340 & No & 2011 & 0.2747 & 0.0150 & Yes \\
\hline 2004 & 0.0861 & 0.1130 & No & 2012 & 0.2640 & 0.0130 & Yes \\
\hline 2005 & 0.0966 & 0.0930 & No & 2013 & 0.2481 & 0.0190 & Yes \\
\hline 2006 & 0.1367 & 0.0700 & No & 2014 & 0.2376 & 0.0220 & Yes \\
\hline 2007 & 0.1793 & 0.0440 & Yes & 2015 & 0.2352 & 0.0180 & Yes \\
\hline 2008 & 0.1853 & 0.0480 & Yes & 2016 & 0.2311 & 0.0200 & Yes \\
\hline
\end{tabular}



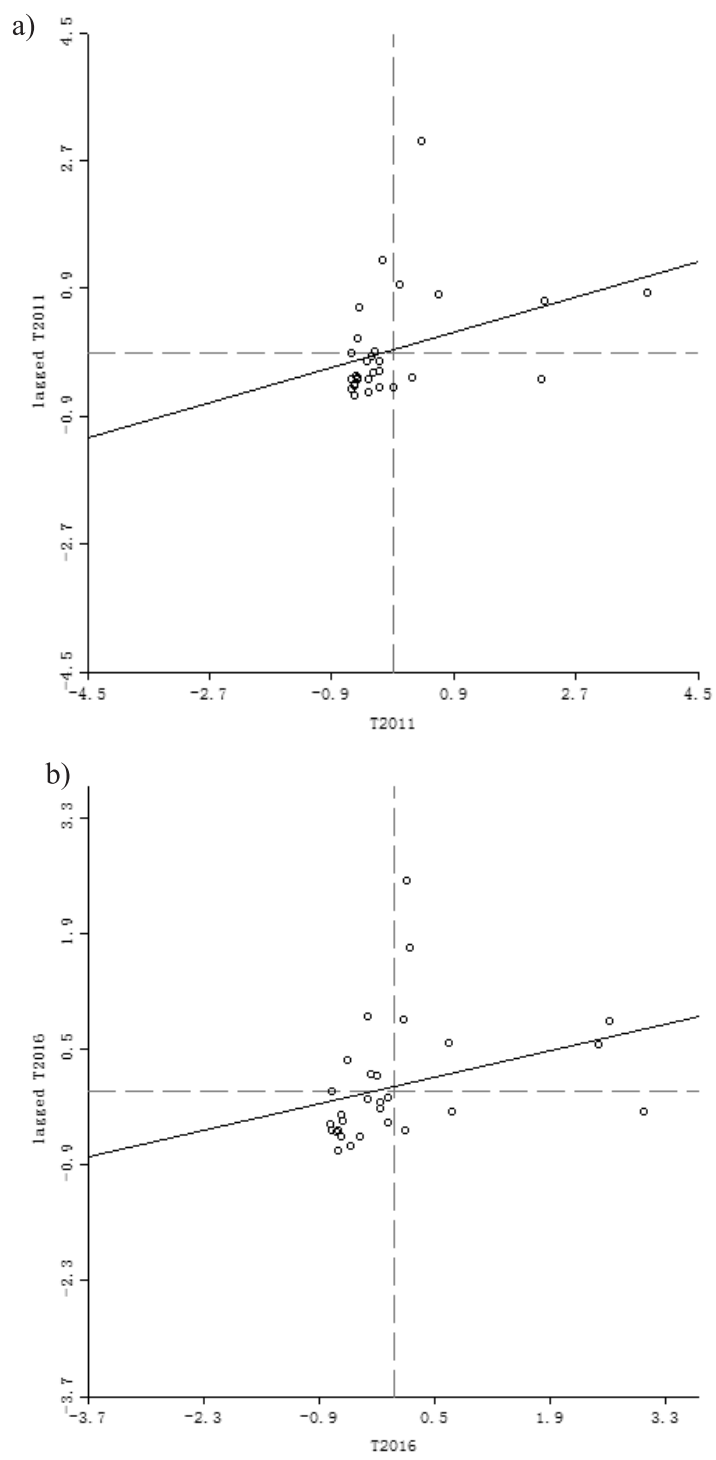

Fig. 1. MSD in terms of authorized patent in a) 2011, b) 2016.

technical progress effects in the upper reaches of the Yangtze River Economic Delta has gradually formed and plays a role, taking Sichuan as the center. In MSD of 2016, the first quadrant includes Jiangsu, Zhejiang,
Anhui, Fujian, Shanghai and Shandong provinces. They are mainly located in the Yangtze River Delta and only Shandong surrounds the Beijing-Tianjin-Hebei region in China. The Yangtze River Delta has become a technical output center.

\section{Econometric Model Estimation Results \\ Variables and Descriptions}

In this research, carbon dioxide emission is chosen as the explained variable of the model to reveal the low carbon transformation process in China. Provincial emission is obtained based on Intergovernmental Panel on Climate Change (IPCC), and carbon emission coefficients of energy types are from its annual report (IPCC 2006) [30]. Eight energy types are considered to estimate carbon dioxide emissions: coal, coke, crude oil, gasoline, kerosene, diesel oil, fuel oil and natural gas (Table 2).

In Table 2, seven variables are introduced into the econometric model as the explanatory variables. Among them, authorized patent scale is regarded as the core variable to reveal technical influences on carbon dioxide emissions in the model. Data are from the China Statistical Yearbook on Science and Technology [31]. GDP is concluded in the model to reveal economic growth influence on emissions. To avoid price fluctuations, it is converted into real values at the fixed price in the year 2000. Population scale is also chosen into the model. It is a timing indicator and population scale of year $t$ is the average value at the end of the year $t$ and $t-1$. Industrial structure and energy consumption structure are both concluded into the model to indicate structural adjustment influences during the research period. Industrial value-added proportion in GDP is used to reveal economic structure adjustment. Coal proportion in energy consumption is used to reveal energy structure state in the model. Foreign spillovers are referred to the technologies accompanied with foreign investment and trades. Foreign direct investment $(F D I)$ is introduced into the model as an explanatory variable. Technology

Table 2. Variable definitions and descriptive statistics.

\begin{tabular}{|c|c|c|c|c|c|c|}
\hline Variable & Definition & Unit & Mean & Std. Dev. & Min & Max \\
\hline $\mathrm{CO}_{2}$ & Carbon dioxide emissions & $10^{4}$ tons & 32389 & 24981 & 1164 & 147193 \\
\hline$G D P$ & Gross domestic production & $10^{8} \mathrm{RMB}$ & 9469 & 9221 & 292 & 50976 \\
\hline$P o p$ & Population scale & $10^{4}$ persons & 4380 & 2635 & 521 & 10924 \\
\hline$I S$ & Economic structure & Percent & 46 & 8 & 19 & 62 \\
\hline$E S$ & Energy consumption structure & Percent & 68 & 17 & 10 & 98 \\
\hline$P a t$ & Granted patent scale & Piece & 1353 & 42261 & 70 & 269944 \\
\hline$F D I$ & Foreign direct investment & $10^{4}$ dollars & 519975 & 659586 & 1495 & 3575956 \\
\hline Tim & Imported technology value & $10^{4}$ dollars & 75347 & 146096 & 0.02 & 971292 \\
\hline
\end{tabular}


Table 3. Stability test results of the eight variables.

\begin{tabular}{|c|c|c|c|c|c|c|c|}
\hline \multirow{2}{*}{ Variables } & \multicolumn{2}{|c|}{ LLC Test } & \multicolumn{2}{c|}{ Fisher-ADF Test } & \multicolumn{2}{c|}{ Fisher-PP Test } & \multirow{2}{*}{ Conclusions } \\
\cline { 2 - 8 } & $\ln (\cdot)$ & $d \ln (\cdot)$ & $\ln (\cdot)$ & $d \ln (\cdot)$ & $\ln (\cdot)$ & $d \ln (\cdot)$ & \\
\hline $\ln C O_{2}$ & 1.044 & $-11.927^{* * *}$ & $11.748^{* * *}$ & $195.105^{* * *}$ & 9.482 & $248.171^{* * *}$ & $\mathrm{I}(1)$ \\
\hline $\ln G D P$ & 9.677 & $-5.514^{* * *}$ & 9.177 & $76.155^{*}$ & 7.471 & $189.089^{* * *}$ & $\mathrm{I}(1)$ \\
\hline $\ln P o p$ & $-4.661^{* * *}$ & $-12.948^{* * *}$ & 60.131 & $215.031^{* * *}$ & $78.995^{* *}$ & $364.279^{* * *}$ & $\mathrm{I}(1)$ \\
\hline $\ln F D I$ & 0.147 & $-16.770^{* * *}$ & 65.607 & $178.364^{* * *}$ & $78.036^{*}$ & $230.287^{* * *}$ & $\mathrm{I}(1)$ \\
\hline $\ln P a t$ & 2.702 & $-13.650^{* * *}$ & 10.456 & $175.925^{* * *}$ & 11.453 & $272.132^{* * *}$ & $\mathrm{I}(1)$ \\
\hline $\ln T i m$ & 3.652 & $-16.877^{* * *}$ & 17.069 & $301.576^{* * *}$ & 14.976 & $432.259^{* * *}$ & $\mathrm{I}(1)$ \\
\hline $\ln E S$ & -1.119 & $-14.210^{* * *}$ & 27.657 & $220.108^{* * *}$ & 25.404 & $302.789^{* * *}$ & $\mathrm{I}(1)$ \\
\hline $\ln I S$ & -0.6302 & $-14.357^{* * *}$ & 25.659 & $173.134^{* * *}$ & 22.808 & $249.595^{* * *}$ & $\mathrm{I}(1)$ \\
\hline
\end{tabular}

Note: $* * *, * *$ and $*$ represent $\alpha=1 \%, 5 \%$ and $10 \%$.

purchase scale is also an explanatory variable to reveal technology import investment scale of provinces. Data are mainly from the China Statistical Yearbook 2017 and China Energy Statistical Yearbook 2017 [32-33].

\section{Stability and Co-Integration Test Results}

Table 3 is stability test results for all eight variables in this model. $d \ln (\cdot)$ is the first-order difference sequence of variables. According to LLC, Fisher ADF and Fisher PP tests results, eight variables are not stable in their logarithm form at $10 \%$ confidence level. The first-order difference sequences for variables have turned into stable state and they are in the same order in stable tests. Thus, the co-integration test can be implemented to decide whether the econometric model should be constructed in this section. Table 4 is the Kao test results for co-integration test for all variables. Based on ADF statistic values in the Kao test, its p-value is 0.0005 and null hypothesis should be refused. There exist stable long-term equilibrium relationships among eight variables, and the econometric model can be constructed. Thus the economic model is suitable to estimate factor analysis on carbon dioxide emissions and the basis model is as follows in Eq. (2). $\varepsilon$ is a random variable to explain the accidental variable's influence:

$\ln \mathrm{CO}_{2}=f(\ln G D P, \ln P o p, \ln I S, \ln E S, \ln P a t, \ln F D I, \ln T i m)+\varepsilon$

Table 4. Panel data co-integration test results.

\begin{tabular}{|c|c|c|c|}
\hline Test method & Statistic & Statistic value & p-value \\
\hline Kao test & ADF & -3.3072 & 0.0005 \\
\hline
\end{tabular}

\section{Statistical Tests for Model form Selection}

Table 5 is the result of the fixed-effect model form selection for panel data econometric model. Main statistics are $R^{2}$, Log-L, LM-lag, LM-error, robust LM-lag and robust LM-error in this section. Based on $R^{2}$ statistic values of models (1)-(4), $R^{2}$ in models (2) and (4) are 0.9731 and 0.9763 , which are higher than those in models (1) and (3). Test results indicate that models (2) and (4) have more goodness of fit than that in the other two. During $L o g-L$ results in Table 5, values in models (2) and (4) are more than the others. It also proves that models (2) and (4) are a better choice among the four forms. Among the four LM test results, three statistics of model (2) are significant, while the four LM statistics of model (4) are not significant. Thus, model (2) should be chosen as the common panel data econometric model.

With Table 6 and Table 7 test results, spatial effects characters are implemented into the common panel data model and converted into spatial panel data model. Table 6 is the Moran index significance test results for carbon dioxide emissions during 2001-2016. It kept 'rising $\rightarrow$ peak $\rightarrow$ decline' trends and was a significant variable at $1 \%$ confidence level. Spatial spillover effects should not be ignored from influential factors, and the spatial econometric model should be constructed in this section. With results in Table 7, $R^{2}$ and $L o g-L$ statistical values are more than results of model (2) in Table 5, and model fitness degree becomes more. With results in Wald and $L R$ tests, null hypotheses are all rejected. These indicate that SDM cannot be converted into SLM or SEM in this research, and its estimation results have better statistical features. In summary, SDM under individual fixed effect form is the most proper economic model in order to analyze influential effects upon emissions in this research. The SDM with seven explanatory variables are as follows in Eq. (3): 
Table 5. Statistical test results for fixed-effect form selection in panel data model.

\begin{tabular}{|c|c|c|c|c|}
\hline Test statistics & Model (1) & Model (2) & Model (3) & Model (4) \\
\hline$R^{2}$ & 0.7819 & 0.9731 & 0.7867 & 0.9763 \\
\hline Log-L & -227.9276 & 274.5369 & -222.6154 & 305.0197 \\
\hline LM-lag & 0.2467 & 1.2630 & $29.0815^{* * *}$ & 0.2425 \\
\hline Robust LM-lag & 0.9030 & $6.1683 * * *$ & 1.0521 & 1.8681 \\
\hline LM-error & $44.2480^{* * *}$ & $18.0501 * * *$ & $44.6008^{* * *}$ & 1.1433 \\
\hline robust LM-error & $44.9043^{* * *}$ & $22.9555^{* * *}$ & $16.5713^{* * *}$ & 2.7689 \\
\hline
\end{tabular}

Note: Model (1)-(4) represents mixed, individual, time and dual fixed effect model forms, respectively; ${ }^{* * *}, * *$ and $*$ represent confidence level $\alpha=1 \%, 5 \%$ and $10 \%$.

$\ln \mathrm{CO}_{2}=\alpha+\lambda W \ln C \mathrm{O}_{2}+\beta_{1} \ln P a t+\beta_{2} \ln G D P+\beta_{3} \ln P o p+\beta_{4} \ln I S+\beta_{5} \ln E S$ $+\beta_{6} \ln F D I+\beta_{7} \operatorname{lnTim}+\delta_{1} W \ln P a t+\delta_{2} W \ln G D P+\delta_{3} W \ln P o p+\delta_{4} W \ln I S$ $+\delta_{5} \operatorname{WlnES}+\delta_{6}$ WlnFDI $+\delta_{7}$ Wh Tim $+\varepsilon$

\section{Parameter Estimation Results and Analysis}

Parameters of SDM in Eq. (3) are estimated with maximum likelihood estimation (MLE) method [34]. With the aid of Matric Laboratory (Matlab) software, parameter estimation results are obtained and shown in Table 8. In comparison, estimation results in CPDEM are also shown in Table 8 . There are significant differences among the two model estimation results.

In SDM, $\beta_{i}$ indicates the regional effect upon its own carbon dioxide emissions and $\delta_{i}$ reveals its impacts on its neighbors' carbon dioxide emissions. Lesage and Pace (2009) proposed a partial differential method to estimate the indirect effects and total effects of each factor [35] and they are shown in Table 9. There is little difference between the direct effect results under partial differential method and the parameter estimations in SDM. The indirect effects for all variables in SDM are apparently different from estimation results with Lesage's method. Total effect of a variable is the sum of direct and indirect effects and they reveal the influential effect of an explanatory variable in a whole. Influential effect analysis is mainly based on them.

As the core explanatory variable, technical progress influences carbon dioxide emissions in a complex way. Firstly, it influences its own carbon dioxide emissions in a negative direction. According to Table 8, its direct effect is -0.0414 . When technical output increased by one percent, it leads to 0.0414 percentage decline in carbon dioxide emissions of its own. Compared with the estimator in CPDEM, it is -0.0789 . The absolute value of direct effect is lower than the estimator in CPDEM. The influential effect of technical progress upon its carbon dioxide emissions is overestimated under CPDEM framework. In terms of estimator significance test, it is not significant even at a confidence level of $10 \%$ in Table 8 . In SDM estimation results, -0.0430 is significant at confidence level $10 \%$. Its estimation result -0.0789 in CPDEM is a significant estimator at confidence level $1 \%$. In summary, technical progress of a province leads to a negative effect on its own emissions in a weak way. This conclusion revises the former conclusions under the CPDEM framework. When we neglect spatial spillovers among provinces, its effect is overestimated. Meanwhile, the technical output structure is weakly dominated by clean technical output. The R\&D investment in green technical progress field should be continuously expanded in order to exert its

Table 6. Moran I significance test of provincial carbon dioxide emissions $(\alpha=5 \%)$.

\begin{tabular}{|c|c|c|c|c|c|c|c|}
\hline Year & Moran I & p-value & Significance Test & Year & Moran I & p-value & Significance Test \\
\hline 2001 & 0.2618 & 0.015 & Yes & 2009 & 0.2849 & 0.007 & Yes \\
\hline 2002 & 0.2556 & 0.013 & Yes & 2010 & 0.2856 & 0.006 & Yes \\
\hline 2003 & 0.2409 & 0.024 & Yes & 2011 & 0.2872 & 0.005 & Yes \\
\hline 2004 & 0.2784 & 0.009 & Yes & 2012 & 0.2712 & 0.010 & Yes \\
\hline 2005 & 0.3050 & 0.005 & Yes & 2013 & 0.2656 & 0.007 & Yes \\
\hline 2006 & 0.2995 & 0.005 & Yes & 2014 & 0.2544 & 0.015 & Yes \\
\hline 2007 & 0.2946 & 0.008 & Yes & 2015 & 0.2555 & 0.013 & Yes \\
\hline 2008 & 0.3044 & 0.005 & Yes & 2016 & 0.2404 & 0.015 & \multicolumn{2}{|c|}{ Yes } \\
\hline
\end{tabular}


Table 7. Statistical tests results of SDM.

\begin{tabular}{|c|c|c|c|}
\hline Test statistics & Statistical value & p-value & Conclusions \\
\hline$R^{2}$ & 0.9821 & - & Good \\
\hline Log-L & 367.32 & - & Apparent improved \\
\hline Wald_spatial_lag & 220.85 & 0.000 & Reject $H_{0}$ \\
\hline Wald_spatil_error & 116.70 & 0.000 & Reject $H_{0}$ \\
\hline LR_spatial_lag & 185.26 & 0.000 & Reject $H_{0}$ \\
\hline LR_spatial_error & 157.45 & 0.000 & \\
\hline
\end{tabular}

emission reduction driving effects in the future. The inadequacy feature of technical development is apparent in the current stage. Especially clean technical progress development is the most potential driving factor to accelerate low carbon transformation in China.

Secondly, the parameter estimator of is 0.0426 in Table 8 is not significant even at confidence level $10 \%$. This indicates that technical output increases by one percent, leading to a $0.0426 \%$ rise in its neighbor's carbon dioxide emissions. They vary in the same direction. Based on Table 8, the total indirect effect is 0.0406 and is not significant, either. The total effect of technical progress is -0.0008 and is close to zero. These results indicate that technical progress influences other provinces' emissions by technical progress spillovers. Though technical progress spillovers among provinces are significant, their indirect effects on emissions are not significant. The whole effect of technical progress on emissions in China is almost zero. This proves that regional technical progress leads not only to declining emissions of its own and others in this stage of China.

From analysis in Section 1, the technology output of most regions in China has developed at a higher speed during the research period. Why did technical progress not bring about emissions reduction? The answer lies in its spatial features. Based on MSD of provincial authorized patent output, it is a lower-level, positive spatial distribution state. Although it is significant, most provinces are located in the 'L-L' type of the MSD. These indicate that most provinces of lower technical progress outputs are spatial clusters, and this spatial distribution state is not in favor of technical progress spillover among provinces. There are only a few southeastern provinces which are

Table 8. Parameter estimation results of SDM and CPDEM (individual fixed effect form).

\begin{tabular}{|c|c|c|c|c|c|c|c|}
\hline \multirow{2}{*}{\multicolumn{2}{|c|}{ Explanatory variables }} & \multicolumn{3}{|c|}{ SDM } & \multicolumn{3}{|c|}{ CPDEM } \\
\hline & & Parameters & t-statistics & p-value & Parameters & t-statistics & p-value \\
\hline \multirow{2}{*}{ Core variables } & $\beta_{1}$ & $-0.0430^{*}$ & -1.6804 & 0.0929 & $-0.0789 * * *$ & -3.2666 & 0.0012 \\
\hline & $\delta_{1}$ & 0.0426 & 1.2579 & 0.2084 & - & - & - \\
\hline \multirow{13}{*}{$\begin{array}{l}\text { Controlled } \\
\text { variables }\end{array}$} & $\beta_{2}$ & $1.3358 * * *$ & 19.5526 & 0.0000 & $0.8231 * * *$ & 15.7874 & 0.0000 \\
\hline & $\beta_{3}$ & $-0.2946^{*}$ & -1.7013 & 0.0889 & $-0.0529 *$ & -0.3328 & 0.7385 \\
\hline & $\beta_{4}$ & $0.2710 * * *$ & 3.5033 & 0.0005 & $0.7418^{* * *}$ & 9.2244 & 0.0000 \\
\hline & $\beta_{5}$ & $0.0914 *$ & 1.8603 & 0.0628 & $0.0926^{*}$ & 1.7406 & 0.0824 \\
\hline & $\beta_{6}$ & -0.0079 & -0.6567 & 0.5114 & -0.0230 & -1.6289 & 0.1040 \\
\hline & $\beta_{7}$ & -0.0021 & -0.4466 & 0.6551 & $0.0139 *$ & 1.7953 & 0.0733 \\
\hline & $\delta_{2}$ & $-0.6996 * * *$ & -6.9355 & 0.0000 & & & \\
\hline & $\delta_{3}$ & $0.6637^{*}$ & 1.8931 & 0.0583 & & & \\
\hline & $\delta_{4}$ & $0.7760 * * *$ & 5.3708 & 0.0000 & & & \\
\hline & $\delta_{5}$ & $0.4467 * * *$ & 3.5453 & 0.0004 & & & \\
\hline & $\delta_{6}$ & $-0.1270 * * *$ & -5.1566 & 0.0000 & & & \\
\hline & $\delta_{7}$ & -0.0085 & -1.0064 & 0.3142 & & & \\
\hline & $\lambda$ & $0.2880 * * *$ & 5.1205 & 0.0000 & & & \\
\hline
\end{tabular}

Note: ${ }^{* * *}, * *$ and $*$ represent confidence level $\alpha=1 \%, 5 \%$ and $10 \%$. 
Table 9. Direct, indirect and total effects of explanatory variables.

\begin{tabular}{|c|c|c|c|c|c|c|}
\hline \multirow{2}{*}{ Explanatory variables } & \multicolumn{2}{|c|}{ Direct effects } & \multicolumn{2}{c|}{ Indirect effects } & \multicolumn{2}{c|}{ Total effects } \\
\cline { 2 - 7 } & Estimator & t-statistics & Estimator & t-statistics & Estimator & t-statistics \\
\hline $\ln P a t$ & -0.0414 & -1.6363 & 0.0406 & 1.0230 & -0.0008 & -0.0194 \\
\hline $\ln G D P$ & $1.3141^{* * *}$ & 19.6749 & $-0.4185^{* * *}$ & -3.8768 & $0.8956^{* * *}$ & 9.2988 \\
\hline $\ln P o p$ & -0.2512 & -1.4919 & $0.7717^{*}$ & 1.7821 & 0.5204 & 1.2810 \\
\hline $\ln I S$ & $0.3323^{* * *}$ & 4.4145 & $1.1510^{* * *}$ & 6.6040 & $1.4833^{* * *}$ & 7.9708 \\
\hline $\ln E S$ & $0.1230^{* *}$ & 2.4201 & $0.6337^{* * *}$ & 3.6286 & $0.7567^{* * *}$ & 3.7342 \\
\hline $\ln F D I$ & -0.0165 & -1.3267 & $-0.1735^{* * *}$ & -4.8070 & $-0.1900^{* * *}$ & -4.5583 \\
\hline $\ln T i m$ & -0.0030 & -0.6106 & -0.0129 & -1.1112 & -0.0159 & -1.1318 \\
\hline
\end{tabular}

Note: $* * * * *$ and $*$ represent confidence level $\alpha=1 \%, 5 \%$ and $10 \%$.

divided into ' $\mathrm{L}-\mathrm{L}$ ' type in terms of technical progress. In 2016, there are 4 and 3 provinces which belong to the 'L-H' and 'H-L' types. These two types are beneficial to optimize spatial distribution with respect to technical progress. During 2001-2016, the quantity of the two types is rising and they are in the minority among the provinces in China. The spatial distribution state restricts its reduction effects on carbon dioxide emissions by technology diffusion mechanism in China. According to technical progress research by Aghion (1992) [36], technical progress is classified into two categories: dirty and clean technical progress. Dirty technical progress points to new technologies characterized by pollutant emissions rising of some industrial production sectors in the economy. Clean technical progress refers to some certain new technologies and they will produce fewer pollutant emissions. When technology output of an economic entity is dominated by clean technical progress, technical progress leads to fewer emissions. Otherwise, dirty technology progress will cause emissions to rise in the economic entity.

In summary, the clean character of technical progress is appearing up and it is still a weak factor for reducing carbon emissions among provinces at this stage. Technical progress remains unstable and its influential elasticity coefficient is about -0.0414 . The indirect effect is approximately 0.0406 through spatial spillovers from other provinces and it is a weak, positive factor in terms of carbon dioxide emissions. To sum up, total effects on carbon dioxide emissions from technical progress is almost close to zero. This means that technical progress cannot exert significant effects upon carbon emissions whether of its own or of its neighboring provinces. The inadequacy and unbalanced development characters in terms of technological progress are becoming more and more obvious in China. In the future, how to promote technical progress to develop at a higher speed and to optimize its spatial distribution should be the most potential factor to accelerate low-carbon transformation in China.
Among the other explained variables, regional economic growth has significant influences on whether on its own carbon emissions or on others' emissions. Its direct effect is 1.3141 and indirect effect is -0.4185 . It is underestimated in the CPDEM framework. Economic development of a province drives its carbon dioxide emissions in the same direction while it drives other emissions in a negative direction. In total, economic growth leads to rising emissions significantly. Meanwhile, spatial distribution optimization in terms of economic development is beneficial for China to accelerate its low carbon emission transformation process. At the same time, economic growth quality is being improved during the research period.

Based on estimation results in Table 9, industrial structure has a positive and significant impact on carbon dioxide emissions. Total effect is 1.4833 and is much higher than the direct effect 0.3323. For every percentage down in industrial structure, 0.3323 percentages of carbon emissions result from it. In addition, it plays more reduction effects upon their neighbors' emissions by economic structure adjustment. It shall be an important potential direction to reduce carbon emissions.

In Table 9, energy consumption type structure is a significant explanatory variable at confidence level $10 \%$. Meanwhile, it also impacts a more indirect effect on their neighbors through spatial spillovers among provinces. They vary in the same directions. Reducing coal consumption in China can greatly accelerate carbon dioxide emissions downward. How to stimulate cleaner energy consumption is a good choice whether in goods production or in life. To accelerate clean energy technology development is essential to realizing energy consumption transformation.

For population scale variable, its indirect effect is a significant estimator in Table 9. The direct and total effects are not significant. The population growth doesn't lead to carbon emissions rising apparently, while population mobility among provinces maybe stimulates carbon dioxide emissions of neighbors. Foreign direct 
Table 10. Robust test results of SDM.

\begin{tabular}{|c|c|c|c|c|c|c|c|}
\hline \multirow{2}{*}{\multicolumn{2}{|c|}{ Explanatory variables }} & \multicolumn{2}{|c|}{ Robust test 1} & \multicolumn{2}{|c|}{ Robust test 2} & \multicolumn{2}{|c|}{ Robust test 3} \\
\hline & & Parameters & p-value & Parameters & $\mathrm{p}$-value & Parameters & p-value \\
\hline \multirow{2}{*}{ Core variables } & $\beta_{1}$ & -0.0028 & 0.9009 & 0.0220 & 0.2575 & -0.0140 & 0.6128 \\
\hline & $\delta_{1}$ & 0.0457 & 0.1601 & 0.0089 & 0.7420 & 0.0083 & 0.8376 \\
\hline \multirow{13}{*}{$\begin{array}{c}\text { Controlled } \\
\text { variables }\end{array}$} & $\beta_{2}$ & $1.2743 * * *$ & 0.0000 & $1.2211 * * *$ & 0.0000 & $1.3811 * * *$ & 0.0000 \\
\hline & $\beta_{3}$ & 0.2195 & 0.2057 & -0.1527 & 0.3458 & -0.2705 & 0.2752 \\
\hline & $\beta_{4}$ & $0.2903 * * *$ & 0.0002 & $0.3107 * * *$ & 0.0001 & 0.0476 & 0.6789 \\
\hline & $\beta_{5}$ & $0.0982 * *$ & 0.0464 & $0.1097 * *$ & 0.0293 & $-0.2123 * *$ & 0.0109 \\
\hline & $\beta_{6}$ & -0.0090 & 0.4559 & -0.0076 & 0.5312 & -0.0021 & 0.8999 \\
\hline & $\beta_{7}$ & -0.0016 & 0.7262 & -0.0006 & 0.8980 & -0.0034 & 0.6340 \\
\hline & $\delta_{2}$ & $-0.7205^{* * *}$ & 0.0000 & $-0.6566 * * *$ & 0.0000 & $0.6185 * * *$ & 0.0001 \\
\hline & $\delta_{3}$ & $0.5847 *$ & 0.0937 & 0.4568 & 0.1683 & 0.1637 & 0.7614 \\
\hline & $\delta_{4}$ & $0.7867 * * *$ & 0.0000 & $0.7202 * * *$ & 0.0000 & $0.1311 * * *$ & 0.0015 \\
\hline & $\delta_{5}$ & $0.4742 * * *$ & 0.0002 & $0.4778 * * *$ & 0.0002 & $0.5057 * *$ & 0.0361 \\
\hline & $\delta_{6}$ & $-0.1240 * * *$ & 0.0000 & $-0.1185 * * *$ & 0.0000 & $-0.1328 * * *$ & 0.0000 \\
\hline & $\delta_{7}$ & -0.0078 & 0.3481 & -0.0070 & 0.4029 & $-0.0352 * *$ & 0.0210 \\
\hline & $\lambda$ & $0.2860 * * *$ & 0.0000 & $0.2740 * * *$ & 0.0000 & $0.1520 *$ & 0.0785 \\
\hline
\end{tabular}

investment (FDI) leads to indirect and total effects upon carbon emissions significantly. The effects of FDI are negative and FDI influences carbon dioxide emissions in a negative direction. Pollution heaven phenomenon does not happen in China during 2001-2016. Conversely, FDI relieves environmental pressure by technological progress spillovers from other countries.

\section{Robust Tests of Model Results}

To test parameter estimation results robustness, three robust tests were implemented in this section. And the results are presented in Table 10. Tests 1 and 2 are two substitute variables for the core explanatory variable chosen to explore results robustness. They are domestic application for patent received indicator for provinces and invention granted by regions during 2001-2016. Test 3 is chosen for the middle part of the research period (2005-2012) and all parameters are estimated. Based on test results, parameter estimators of core variables are insignificant at $10 \%$ confidence level in the three tests and accord with the above conclusion in Table 9. Its spatial lag coefficients are also insignificant at $10 \%$ confidence level. Technical progress doesn't play a significant role in carbon emissions for provinces in China. For the other six explanatory variables, significance tests keep in accordance with that in SDM. Moreover, signs of parameters in the three tests are in the same with that in SDM. Upon the above analysis, parameters in SDM are robust and the corresponding analysis is reliable to convert into conclusions.

\section{Conclusions and Implications}

\section{Main Conclusions of this Research}

Based on the above empirical analysis, the main conclusions are as follows:

Firstly, parameters estimation results under SDM have revised original results under the CPDEM framework. They can reflect the influential effects of technical progress on carbon dioxide emissions in China more accurately. Based upon Moran I significance test results of carbon dioxide emissions among 30 provinces, they represent significant, lower positive distribution states during 2001-2016. Spatial effects should be introduced into CPDEM, and SPDEM is a better choice to analyze its influential factors of carbon dioxide emissions. From statistical tests, SDM cannot be converted into SLM or SEM. Parameter estimation results show good statistical property and are more suitable to analyze carbon dioxide emissions factors in this research. According to estimation results, the direct effect of technical progress is -0.0414 and is lower than that in CPDEM (0.0789). Technical progress is a negative driving force to influence provincial carbon dioxide emissions. Its indirect effect is 0.0406 and is not significant. The total effect of technical progress on emissions is -0.0008 and much closer to zero. Technical progress didn't play a significant role in driving the low carbon dioxide transformation process during 2001-2016.

Secondly, inadequate and imbalanced development in terms of technical progress is a barrier to promote 
its carbon emission reduction effects at this stage. How to develop technical progress among provinces is the most potential force to realize low carbon transformation targets in the future. On one hand, technical progress has a negative impact on its own carbon dioxide emissions. As it is lower and insignificant, inadequate development of technical progress is much more apparent among regions in China. Especially green technical progress development should be given increasing effort in the future. Although technical progress has significant spatial spillovers among provinces, it still plays a weak positive role on neighbors' carbon dioxide emissions in the research period. The spatial distribution state is lower, positive 'L-L' type and is maybe the cause of hampering technical spillover effects. This mechanism is not beneficial for provinces to spatial spillovers among the low carbon transformation process.

\section{Policy Recommendations}

Firstly, it is an important step to energetically accelerate cleaner technical progress in order to strengthen its reduction effects on carbon dioxide emissions. Especially low carbon technology should be given more and more effort for stimulating its development in the future. Only by this way does technical progress convert it into a more significant factor to push the transformation process in China. Pollution technologies characterized by high energy consumption and high pollutant emissions should be strictly controlled from the whole process. This should be the long-term technical development strategy in China. In order to promote low-carbon technology development, three aspects should be paid more focus. They are divided into types and are no carbon technologies, carbon reduction technologies and $\mathrm{de}^{-}$carbonation technologies. No carbon emission technology intends to control carbon emissions from the source. Clean energy types emitting zero emissions and replacing fossil energies with clean energy types is the best choice for low-carbon transformation. Solar, wind or geothermal energies are good examples for developing technologies. Carbon reduction technologies are a kind of process control technology. This kind of technology is intended to improve efficiency and lower emissions during goods production and consumption. Technologies as integrated gasification combined cycle (IGCC), combined heat and power (CHP), and purification catalyst technologies for volatile organic compounds (VOC) are the types of technologies in power generation and petroleum sectors. De-carbonation technology is a kind of technology to capture, store or recycle carbon dioxide. Carbon Capture and Storge (CCS) is a good example of this type. For these technologies, R\&D fund input, technology output and transformation should be given more incentive policies to stimulate them to develop wholly.

Secondly, spatial distribution optimization of technical progress should be considered and given more focus on when technical development policies are arranged. By this way, cleaner technical spillovers among provinces will accelerate emission reduction effect transmissions. In the end, it will save R\&D funds input and accelerate the whole low carbon transformation process in China. In the current stage, this technical progress distribution state is dominated by ' $\mathrm{L}-\mathrm{L}$ ' spatial cluster mode, which is not suitable for provinces to have technical spillovers among them. Provinces of ' $\mathrm{H}-\mathrm{H}$ ' type are mainly located in the Yangtze River Delta region of China and they are Shanghai, Zhejiang and Jiangsu provinces. These provinces are the most developed economic region in China and are rich in R\&D resources. This region also develops quickly with respect to regional coordinated development. As the preferential development regions in regional coordinated development, although such regions as Yangtze River Delta, Pearl River Delta and Beijing-Tianjin-Hebei have some technology agglomeration, they haven't formed high-level technical clusters and related industrial sector clusters. Spatial spillovers in clean technology fields do not radiate well into their outside regions. As the central nodes of technical progress transmission network in China, more R\&D resources and incentive policies should be given to these regions and more resources should be input into clean technical progress research of the regions. More incentive policies are made to stimulate technology transmission among regions and these will enlarge technical spillover effects during the low-carbon transformation process.

\section{Acknowledgements}

The authors acknowledge financial support from China's Social National Funds (17BGL252), Fundamental Research Funds for China's Central Universities (9160618009), Graduate Students HighQuality Curriculum Construction Funds of North China Electric Power University (130017043) and the Science and Technology Project of State Grid Corporation of China (5211JY180004).

\section{Conflict of Interest}

The authors declare no conflict of interest.

\section{References}

1. BP company. BP Statistical Review of World Energy 2017. https://www.bp.com/ china/ reports-and-publications bp_2017-_html

2. JIA P.R. Technological progress is the core force to drive low carbon development in China. China Economic Times, 2018-4-10, $5^{\text {th }}$ Edition.

3. TOBLER W.R. Philosophy in geography. Theory and Decision Library, 20, 379, 1979.

4. HAN C. Analysis of the influence of technological progress on industrial carbon emissions in China. Journal 
of Dalian University of Technology (Social Sciences), 2, 65, 2018.

5. ZHANG B.B., ZHU J., QUAN X.Y. A theoretical and empirical analysis of technical progress and $\mathrm{CO}_{2}$ emission intensity. Science Research Management, 12, 41, 2017.

6. XIE B., SONG Y.J. Impacts of environmental governance and technological progress on China's low carbon economic efficiency: A study based on super-efficient SBM-VRS model. Ecological Economy, 10, 14, 2017.

7. CHENG Z.H., LI L.S., LIU J. The emissions reduction effect and technical progress effect of environmental regulation policy tools. Journal of Cleaner Production, 149, 191, 2017

8. SUN X., SHEN Y.C., TAO R. Measurement of technical progress and Its Influential effects on carbon emission intensity. Jianghuai Tribune, 6, 64, 2016.

9. JIN P.Z., ZHANG Y.B., PENG X. The double-edged effect of technological progress in carbon dioxide emissions reduction: Empirical evidence from 35 sub-industrial sectors in China. Studies in Science of Science, 5, 706, 2014.

10. LI K.J., QU R.X. Impact of technological change on carbon dioxide emission: An empirical analysis based on provincial dynamic panel data model. Journal of Beijing Normal University (Social Sciences), 5, 129, 2012.

11. ZHANG C.J., ZHANG Z.Y. Spatial effects of energy resources and technology advance on China's carbon emission intensity. China Population, Resources and Environment, 9, 37, 2015.

12. WEI W.X., YANG F. Impact of technology advance on carbon dioxide emission in China. Statistical Research. 7, 36,2010

13. HUANG J., DING G. Threshold effects research of technical progress on carbon intensity. Science and Technology Progress and Policy, 18, 22, 2014.

14. YIN J.H., ZHENG M.Z., CHEN J. The effects of environmental regulation and technical progress on $\mathrm{CO}_{2}$ Kuznets curve: An evidence from China. Energy Policy, 77, 97, 2015

15. ZHANG H., XU K.N. Impact of environmental regulation and technical progress on industrial carbon productivity: An approach based on proxy measure. Sustainability, 8, 819, 2016.

16. ZHOU Z.M., YE X.Y., GE X.Y. The impacts of technical progress on sulfur dioxide Kuznets curve in China: A spatial panel data approach. Sustainability, 9, 674, 2017.

17. ZHAO Q.Z., YAN Q.Y., ZHAO H.R. Research on spatial characteristics and influencing factors of provincial carbon emissions in China. Journal of Beijing Institute of Technology (Social Sciences Edition), 1, 9, 2018.

18. JAFFE A.B., NEWELL R.C., STAVINS R.N. Environmental policy and technological change. Environmental and Resource Economics, 22, 41, 2002.

19. SHEN M., LI K.J., QU R.X. Technical advances, economic growth and carbon dioxide emissions: Theoretical and empirical studies. The Journal of World Economy, 7, 83, 2012.

20. ACEMOGLU D., AGHION P., BURSZTYN L., HEMOUS D. The environment and directed technical change.
National Bureau of Economic Research Working Paper 15451, 2009. http://www.nber.org/papers/w15451

21. YAN Z.M., DENG X.L., CHEN B.D. The impact of green technology progress on the low carbon transformation of China's industrial structure. Comparative Economic \& Social Systems, 4, 25, 2016.

22. SUN N. Carbon emission reduction of manufacturing rely on technical progress. Forum on Science and Technology in China. 4, 44, 2011.

23. LIAO M.Q., XU L.M. IO-SDA model of CO2 Emissions and its empirical research. Statistical Research. 7, 62, 2017.

24. DONG FENG, YU BOLIN, TERGEL HADACHIN, DAI YUANJU, WANG YING, ZHANG SHENGNAN, LONG RUYIN Drivers of carbon emission intensity change in China [J]. Resources, Conservation \& Recycling, 129, 187, 2018.

25. JIANG Q.S., HAN Z.Z. The variable selection for panel semiparametric spatial autoregressive model: The analysis for carbon emissions based on STRIPAT model. Journal of Applied Statistics and Management, 5, 821, 2017.

26. YANG M.G., WANG G.X. Regional differences and influencing factors of carbon emissions in China: Empirical evidence from provincial panel data. Journal of Shandong University (Natural Science), 6, 16, 2017.

27. DONG FENG, LONG RUYIN, LI ZHUOLIN, DAI YUANJU Analysis of carbon emission intensity, urbanization and energy mix: evidence from China [J]. Natural Hazards, 82, 1375, 2016.

28. DONG FENG, BIAN ZHENGFU, YU BOLIN, ZHANG SHENGNAN, LI JINGYUN, SU BIN, LONG RUYIN Can land urbanization help to achieve $\mathrm{CO}_{2}$ intensity reduction target or hinder it? Evidence from China [J]. Resources, Conservation \& Recycling, 134, 206, 2018.

29. DONG FENG, LONG RUYIN, YU BOLIN, WANG YING, LI JINGYUN, WANG YUE, DAI YUANJU How can China allocate $\mathrm{CO}_{2}$ reduction targets at the provincial level considering both equity and efficiency? Evidence from its Copenhagen Accord pledge [J]. Resources, Conservation \& Recycling, 130, 31, 2018.

30. Intergovernmental Panel on Climate Change. IPCC guidelines for national greenhouse gas inventories. Japan: IGES, 2006 [In Japan].

31. National Bureau of Statistics. China Statistical Yearbook on Science and Technology 2017. China Statistical Press, 2018 [In China].

32. National Bureau of Statistics. China Statistical Yearbook 2017. China Statistical Press, 2018 [In China].

33. Department of Energy statistics, National Bureau of Statistics. China Energy Statistical Yearbook 2017. China Statistical Press, Beijing, 2018 [In China].

34. CHEN Q. Advanced Econometrics and Stata application ( $2^{\text {nd }}$ edition). Higher Education Press, Beijing, 2017 [In China].

35. LESAGE J.P., PACE R.K. Introduction to spatial econometrics. CRC press, Tayor \&Francis Group, 2009 [In USA].

36. AGHION P., HOWITT P. A model of growth through creative destruction. Econometrica, 60, 323, 1992. 